\title{
Democratização da gestão da educação avanços e perspectivas
}

\author{
Democratization of education management \\ advances and perspectives
}

\author{
Democratización de la gestión de la educación \\ avances y perspectivas
}

\author{
JANETE MARIA LINS DE AZEVEDO* \\ Universidade Federal de Pernambuco, Recife- PE, Brasil. \\ MARIA DA SALETE BARBOZA DE FARIAS** \\ Universidade Federal da Paraíba, João Pessoa- PB, Brasil.
}

\begin{abstract}
RESUMO: $\mathrm{O}$ artigo, com base no conceito de democracia de Georges Burdeau, aborda a evolução da gestão democrática da educação. Problematiza o caráter autoritário das relações sociais de uma perspectiva histórica, os contextos sócio-políticos da luta pela redemocratização e sua conquista, e a promulgação da Carta Magna. Pontua como o princípio da gestão democrática materializou-se na legislação e na prática da política, pontos de inflexão da gestão nas três décadas, avanços e recuos em face de projetos em disputa, e ameaças à ordem democrática.

Palauras-chave: Gestão democrática da educação básica. 30 anos de Constituição. Retrocessos e resistência.
\end{abstract}

\begin{abstract}
The article, based on the concept of democracy by Georges Burdeau, addresses the evolution of educational management.
\end{abstract}

\footnotetext{
* É mestra em Sociologia pela Universidade Federal de Pernambuco e doutora em Ciências Sociais pela Universidade Estadual de Campinas. Realizou estágios de Pós-doutoramento na Universidade de Paris 8 e na Universidad de València. Atualmente é professora titular da Universidade Federal de Pernambuco. E-mail:<janete.lins@gmail.com>.

** Possui mestrado em Educação pela Universidade Federal da Paraíba e doutorado em Sociologia pela Universidade Federal de Pernambuco e realizou estágio de pós-doutorado na Universidade de Goiás e na Universidade de Valência (2018). Atualmente é professora associada III da Universidade Federal da Paraíba. E-mail: <runasvida@gmail.com>.
} 
It discusses the authoritarian character of social relations through a historical perspective, the social and political context of the struggle for redemocratization and its conquest, and the promulgation of the Magna Carta. It punctuates the principle of democratic management materialized in the legislation and practice of politics, inflection points of management over three decades, advances and setbacks in the facing projects in dispute, and threats to the democratic order.

Keywords: Democratic management of basic education. 30 years of Constitution. Setbacks and resistance.

RESUMEN: Este artículo, basado en el concepto de democracia de Georges Burdeau, aborda una evolución de la gestión democrática de la educación. Problematiza el carácter autoritario de las relaciones sociales desde una perspectiva histórica, los contextos socio- políticos de la redemocratización y su conquista, y la promulgación de la Carta Magna. Muestra como el principio de la gestión democrática se materializó en la legislación y en la práctica política, elementos de inflexión de la gestión en las tres décadas, avances y retrocesos en faz de proyectos en disputa, y amenazas al orden democrático.

Palabras clave: Gestión democrática de la educación básica. 30 años de la constitución. Retroceso y resistencia.

\section{Introdução}

E $\mathrm{m}$ tempos tão adversos para a nossa frágil democracia, o debate sobre a democratização da gestão da educação ganha dimensão especial nesse momento em que a Constituição brasileira completa trinta anos e que o País, mais uma vez, sob o manto de uma distorcida concepção de democracia, assiste à supressão de nossos ainda restritos direitos sociais arduamente conquistados. ${ }^{1}$

Trata-se de um contexto perverso em que, entre outras coisas, vem sendo desfigurada a Constituição, distanciando-a cada vez mais do seu papel de principal instrumento de regulação de uma sociedade democrática, que as forças progressistas intentam construir de há muito e que, mais uma vez, parece ir se perdendo no horizonte. Ao nos referirmos a uma concepção "distorcida" de democracia, estamos admitindo o caráter polissêmico desse conceito. Portanto, de partida, é oportuno esclarecer em qual sentido o estamos utilizando.

Conforme já tratamos em outro espaço (AZEVEDO, 2017), lembramos, antes de tudo, que, como forma de governo, a democracia é indubitavelmente necessária para 
o exercício de outros direitos. Todavia, inspirando-nos em Burdeau, compreendemos que a acepção da democracia como forma de governo é, em certa medida, secundária, tendo em vista que historicamente ela se tornou uma filosofia, um modo de vida. Sendo assim, significa o que realmente é, como também significa a ideia que as pessoas têm dela, visto que nas práticas democráticas depositamos as esperanças de uma vida melhor e participativa. Portanto, é essencial tomá-la na perspectiva de um modo de vida comum, coletivo, cujos mecanismos devem ser conhecidos e vivenciados por todos e todas desde cedo. Para Burdeau (1956), o exercício das práticas democráticas deve acontecer desde cedo nos micro espaços, para, assim, se difundir pelas demais instituições sociais, até chegar às instituições políticas.

Nessa acepção, a democracia se traduz, concomitantemente, como um valor universal, assim reconhecido mundialmente (COUTINHO, 2000; BENEVIDES, 1996), e como um método: meio de atuação, de tomar decisões e, antes de tudo, modo de convivência como acertadamente defenderam, entre outros, Karl Mannheim (1960), John Dewey (1959) e o nosso Paulo Freire (1974). Desta perspectiva, método e valor formam um todo homogêneo "como dimensão fundamental dos processos educativos para que as sociedades se democratizem" (AZEVEDO, 2017, p: 39).

Todavia, a discussão do legado que nos reservam esses trinta anos da Constituição brasileira não pode prescindir também da alusão às nossas ligações com o contexto internacional e, portanto, alusões aos padrões da regulação social que vêm sendo impostos pelos novos rumos do movimento da acumulação em escala planetária, guiados pelo neoliberalismo.

Como apropriadamente analisam Dardot e Laval (2016), para além de uma doutrina econômica o neoliberalismo é um modo de vida, uma "nova razão do mundo". Neste sentido, seus adeptos abominam a convivência entre o capitalismo e a democracia, argumentando que a vigência de direitos e a proteção social ferem o capitalismo no seu cerne pelo desrespeito à liberdade e ao individualismo, valores básicos em que se assenta a doutrina liberal e, por conseguinte, as sociedades de mercado. Assim, o denominado "capitalismo social", que permitiu o alargamento das políticas sociais, é tido como uma grande e insolúvel contradição. Já em 1988 Przeworski e Wallerstein afirmavam que “o capitalismo democrático" se encontrava "na encruzilhada" e escreviam:

O que está envolvido na atual ofensiva de direita não é simplesmente uma questão de impostos, gastos de governo, ou mesmo distribuição da renda. Os planos para abrandar a tributação dos lucros, abolir os controles ambientais, eliminar os programas previdenciários, acabar com o controle do governo sobre a segurança dos produtos e as condições de trabalho e para enfraquecer os sindicatos são muito mais do que uma reorientação da política econômica. Constituem um projeto para uma nova sociedade, uma revolução burguesa [...]Atrás de alternativas econômicas ocultam-se visões de sociedade, modelos de cultura e inclinações pelo poder. Projetos econômicos pressupõem projetos políticos e sociais (p. 43). 
Sem dúvida, permanecemos ainda em uma democracia política. No entanto, todos os artifícios jurídico-políticos criados e que levaram ao "golpe" de 2016, possibilitaram a volta de uma determinada hegemonia na perspectiva da imposição da ordem neoliberal que aglutina, desde há muito, forças contrárias aos interesses da maioria. Essa ordem, guardando as especificidades da realidade brasileira, se fez representar pelo governo Collor, se afirmou durante os governos Fernando Henrique Cardoso, inclusive na educação e sua gestão, e tinha sofrido algum arrefecimento pela resistência de forças democráticas nos governos de Lula da Silva e da presidenta Dilma Rousseff. Mas voltou de modo aguerrido neste período do governo Temer, com a retirada de direitos sociais, e que terá continuidade no programa do presidente eleito, tal como vem sendo amplamente anunciado.

A Constituição, já tão combalida, parece que continuará ferida de morte. No entanto, há terapia: a nossa resistência, como procuraremos discutir ao mostrar, de uma perspectiva histórica, o que ocorreu durante esses anos, destacando perdas e ganhos, de onde partimos e aonde chegamos. Afinal, a realidade é uma construção humana, uma construção social e histórica que se tece a partir da luta dos contrários.

A Constituição de 1988 representa, até agora, a que teve maior período de continuidade, acompanhando e regulando, ela própria, o maior período de vigência da democracia política no Brasil, mas se encontra seriamente ameaçada desde o referido "golpe" de 2016. No entanto, apesar de jovem, o seu envelhecimento se deu precocemente, em face da natureza da maior parte das ementas a que foi sendo submetida desde a sua promulgação, bem como da paralisia que se instalou em relação a um conjunto de leis complementares que deveriam ter sido promulgadas à posteriori. Sobretudo nos últimos dois anos, as emendas a deformaram tanto que estamos praticamente voltando a um tipo de regulação em que a cidadania social era praticamente nula.

Evidente que não desconhecemos a plasticidade inerente ao espírito que presidiu a sua formulação: presciência de revisão, reformulação e emendas, desde que salvaguardadas as cláusulas pétreas garantidoras da ordem democrática e dos direitos de cidadania. Também, não se trata de pensar que a simples promulgação da Carta Magna, em 1988, seria o garante do respeito às suas determinações ao longo do tempo, como se o real e o legal pudessem se confundir totalmente. Bem sabemos que a legislação constitui instrumento das políticas públicas, integrando uma das suas dimensões: faz parte da dimensão normativa (MULLER, 1990). Resulta de disputas travadas em um determinado contexto histórico, podendo ser efêmera ou mais permanente. Contudo, esses aparatos legais

[...]trazem em si determinados princípios, diretrizes e projetos políticos cuja implementação (isto é, sua conversão em fatos da realidade) depende evidentemente da disputa social e política - idealmente arbitrada por regras supostamente republicanas presentes no sistema democrático vigente - que se coloca em movimento desde a sua promulgação (CARDOSO JR, 2018, p: 19). 
A Carta Magna representa a legislação fundamental de uma dada sociedade, reunindo a regulação concernente aos poderes públicos, à forma de governo, à distribuição de competências, a direitos e deveres dos cidadãos e cidadãs, tudo inter-relacionado. De modo interligado, representa a síntese possível dos embates, acordos e consensos de um momento histórico, contendo, portanto, determinada filosofia de ação indicativa do projeto de sociedade conjunturalmente hegemônico. Mas comportaria, por seu caráter de instrumento regulador nas democracias, estratégias capazes de colocar em ação a defesa dos interesses da maioria. Isto a depender das forças políticas em presença, por ser um instrumento de arbitragem, quando as regras mínimas do jogo democrático são respeitadas, o que nem sempre ocorre no nosso país.

Muitas foram os embates ocorridos nas décadas de 1970 e 1980 para que as forças progressistas conseguissem registrar no texto constitucional direitos básicos da pessoa humana que de há muito estavam garantidos em outras sociedades.

Promulgada em 1988, depois dos obscuros anos da ditadura civil militar, a sétima Constituição brasileira foi denominada pelo presidente da Assembleia Nacional Constituinte, deputado Ulysses Guimarães, de Constituição Cidadã, pela conquista da ordem democrata para todos e todas, passados quatro anos do fim do regime de exceção.

Vale lembrar que, desde os anos 1970, a conservadora regulação neoliberal, supressora de direitos das classes trabalhadoras, que preconiza menos Estado e mais mercado, se disseminava pelo mundo capitalista como uma terapia para a superação de mais uma das suas crises cíclicas. A Inglaterra inaugura o modelo com o governo de Margareth Thatcher, dentre outras coisas, com cortes na proteção social, o mesmo ocorrendo mais tarde com o governo de Ronald Reagan nos EUA (AZEVEDO, 2004). Aqui, ao contrário, em certa medida, se caminhava teimosamente na contramão do que ocorria no espaço internacional, graças a ampla mobilização popular, mas isto seria por pouco tempo.

No entanto, naquele momento a Constituição Cidadã permitia uma experiência impar na direção da construção da cidadania, visto que, entre seus avanços, se encontrava o esboço de um sistema de proteção social com alguns traços e valores do Estado de Bem-Estar Social, que estava em causa nos países centrais: universalidade no lugar da focalização; seguridade social no lugar do seguro social e direito no lugar do assistencialismo, como o que até então aqui predominara (FAGNANI, 2017), o que incluiu o reconhecimento da educação como direito público subjetivo. Apesar de todos os limites, é consensual o reconhecimento dos avanços que se estabeleciam na regulação da nossa sociedade naquele momento. Conteúdo do discurso do Deputado Ulisses Guimarães, no dia da sua promulgação, se tornou emblemático:

A Constituição mudou na sua elaboração, mudou na definição dos Poderes. Mudou restaurando a Federação. Mudou quando quer mudar o homem em cidadão. E só é cidadão quem ganha justo e suficiente salário, lê e escreve, mora, tem hospital e remédio, lazer quando descansa. Num país de 30 milhões, 401 mil analfabetos, afrontosos 25 por cento da população, cabe advertir: a cidadania começa com o 
alfabeto. [...]A Constituição certamente não é perfeita. Ela própria o confessa ao admitir a reforma. Quanto a ela, discordar, sim. Divergir, sim. Descumprir, jamais. Afrontá-la, nunca.Traidor da Constituição é traidor da Pátria. Conhecemos o caminho maldito. Rasgar a Constituição, trancar as portas do Parlamento, garrotear a liberdade, mandar os patriotas para a cadeia, o exílio e o cemitério. A persistência da Constituição é a sobrevivência da democracia. Quando, após tantos anos de lutas e sacrifícios, promulgamos o Estatuto do Homem da Liberdade e da Democracia, bradamos por imposição de sua honra: temos ódio à ditadura! Ódio e nojo! (GUIMARÃES, 1988, p. 118-119).

Vale lembrar que os direitos sociais, ainda que no momento se encontrem severamente abalados, integram o Título II do texto constitucional, estão estabelecidos como Direitos e Garantias Fundamentais, têm capítulo específico e envolvem os artigos $6^{\circ}$ ao $11^{\circ}$, abrangendo, originalmente, a educação, a saúde, o trabalho, o lazer, a segurança, a previdência social, proteção da maternidade e da infância e a assistência aos desamparados. Mais tarde, por emenda, foram acrescidos o direito à moradia e ao transporte. A educação, além disso, um direito universal, assume papel de destaque no Título da Ordem Social, com previsão dos recursos para o seu financiamento e prioridades (BRASIL, 1988).

Tal como expresso nas palavras de Ulisses Guimarães, a cidadania requer o usufruto de direitos, acesso a salário justo, à saúde, ao lazer, à educação. Nesta direção é que a educação, reafirmada como direito de todos, foi tomada como dever do Estado, tendo por objetivo o pleno desenvolvimento da pessoa como cidadã e sua preparação para o trabalho. Para o que estava colocada a questão da democratização da educação e da escolarização para todos e todas, implicando, por seu turno, na democratização da gestão da educação e da escola.

Em face das características que historicamente têm marcado as relações sociais no país, o pacto firmando para a promulgação do texto constitucional não significou a ruptura com as práticas conservadoras. Acordos e consensos não chegaram a ser efetivamente estabelecidos, fato explicitado logo após sua promulgação, pelo processo de luta entre dois projetos em disputa: os defensores de uma ordem liberal conservadora, que queria derrogar a Constituição, e o projeto das chamadas forças progressistas, que lutavam e lutam pela vigência dos direitos sociais e pela construção e permanência de uma ordem democrática (CARDOSO JR, 2018; FAGANANI, 2017).

Ao longo desses 30 anos, grosso modo, esses dois projetos, com nuances, e nem sempre podendo ser identificados no seu estado puro, no sentido weberiano do termo, não saíram de cena, influenciando os rumos da sociedade brasileira e, portanto, da nossa política educacional, com a prevalência, mais uma vez, do conservadorismo como estamos a assistir agora. E para a busca da compreensão desse momento presente nunca é demais ir na trilha das suas raízes no passado. 


\section{As restrições à democratização no passado recente}

O modelo excludente e seletivo pelo qual se deu o desenvolvimento do capitalismo relegou a um segundo plano o direito a educação aos moldes republicanos, como de resto ocorreu com o conjunto dos direitos de cidadania. A herança da colonização portuguesa, com as marcas do patrimonialismo e do mandonismo, o arcaísmo das nossas elites, o autoritarismo como marca na articulação das relações sociais, o modo subordinado como nos inserimos no espaço capitalista internacional, são algumas das características que plasmaram o nosso "Estado do Mal Estar Social”, com uma sociedade marcada por profundas desigualdades.

A prevalência dos regimes de exceção, desde que nos tornamos República, traz incrustada no tecido social práticas autoritárias nas diversas formas de manifestação, corriqueiramente simbólicas e pouco combatidas, em face mesmo dos padrões de socialização que pouco incluem o usufruto dos direitos de cidadania. Não obstante, é a partir deste quadro mais geral que podemos compreender as lutas pela gestão democrática da educação no bojo das lutas pela democratização da educação na sua integralidade, no processo que levou à debacle a ditadura civil militar instalada no pós 1964 no País.

Exemplificando a partir da educação básica, lembramos que a política educacional do regime autoritário, ao seu modo, promoveu um significativo aumento da oferta de vagas no ensino fundamental, ampliando os anos de escolaridade obrigatória e gratuita de 4 para 8 anos, o que possibilitou a entrada em massa das classes populares na escola pública. No entanto, isto foi feito sem a preocupação com a oferta de uma educação de qualidade como ocorria quando a clientela era predominantemente das camadas médias, efetivando-se uma expansão praticamente sem os investimentos requeridos para tanto, numa expressiva violência simbólica sobre os até então excluídos da escola.

Os estudos mostram que os gastos com a educação dos governos militares, além de insuficientes, foram decaindo e se sucederam arranjos perversos para dar conta do atendimento da população. Houve a diminuição da jornada escolar, aumento do número de turnos, ampliação das classes multisseriadas e unidocentes, congelamento do salário, precarização do trabalho docente e a contratação de professores leigos. Houve também a criação de licenciaturas de curta duração para, de forma aligeirada, ter profissionais para atender aos novos alunos. Além disso, intensificou-se a privatização da oferta por meio da compra de vagas na rede privada de ensino com os fundos públicos (AZEVEDO, 1995;1994).

As estratégias acionadas permitiram a entrada na escola da população em idade escolar. As taxas de escolarização, das crianças e jovens, passaram de 45,4\%, em 1960, para 85\%, em 1984. Entretanto, as condições da oferta de ensino, desde então, assumiram a perversa característica da baixa qualidade, expressa sobretudo nos altos índices de repetência e abandono escolar, explicitando a negação do direito universal à escola básica (AZEVEDO, 1994). 
O regime autoritário não poderia deixar de estender seus tentáculos à gestão da educação e das escolas. Elas foram submetidas a uma organização com alto grau de hierarquia e verticalização. Proibiu-se os grêmios estudantis como, de resto, todo tipo de entidade representativa do corpo discente e docente nos três níveis de ensino.

As áreas da educação e da cultura, tal como hoje ocorre, sempre são consideradas "perigosas" para as forças conservadores, porque levam ao pensamento crítico.

Não foi diferente no período da ditadura civil militar. As instituições da área educacional, a exemplo do que ocorreu em outras áreas, foram submetidas aos controles políticos e ideológicos então estabelecidos. Pessoas foram expurgadas das escolas, universidades e instituições correlatas, presas, desaparecidas ou se exilaram. Ao mesmo tempo, se procurou adequar os próprios conteúdos trabalhados nos processos de ensino e aprendizagem ao ideário da nova realidade. Além do Ato institucional n. 5, uma medida mais geral que também coibiu o protesto estudantil e a sua organização em qualquer entidade representativa, outro decreto tornou obrigatória a disciplina Educação Moral e Cívica em todos os níveis e modalidades de ensino, por meio de conteúdos sancionados pelos órgãos de censura (GERMANO, 2011). Também foram suprimidas as disciplinas Sociologia e Filosofia do ensino secundário, semelhante ao que estamos a assistir no momento com a reforma do ensino médio. Por um largo período, o próprio Ministério da Educação (MEC) ficou submetido ao sistema de planejamento, que definia as prioridades de acordo com o modelo de desenvolvimento econômico, procurando colocar a educação a serviço dos interesses da produção e do mercado, conforme a perspectiva tecnicista (FRIGOTTO, 1984). Cabia ao MEC transformar as prioridades definidas pelo planejamento em programas (contidos nos planos setoriais de educação). As secretarias estaduais apresentavam ao Ministério os seus projetos de acordo com os programas estabelecidos centralizadamente. A centralização dos recursos na instância federal e os mecanismos estabelecidos para o seu repasse constituíram instrumentos de poder que garantiam a submissão das unidades federadas à política educacional do regime autoritário sem nenhum canal de discussão, inviabilizando qualquer tipo de participação na gestão da educação por parte dos estados e municípios (AZEVEDO, 1994).

Os resultados da política educacional dos governos militares se explicitavam na magnitude dos níveis de evasão e repetência, relegando ao analfabetismo e ao analfabetismo funcional um contingente significativo de adolescentes, de jovens, e de adultos produzidos pela própria escola, para o que também contribuía a precariedade dos resultados de outras políticas sociais que afetava o desempenho dos alunos. Essa situação seria revelada com a queda da ditadura, quando a dívida social legada pelos militares à Nação pode ser denunciada e cobrada.

Integrando, portanto, o processo de redemocratização que teve curso nos anos 1970 e 1980, as forças progressistas tinham nas suas pautas de luta o resgate da dívida para com a educação pública, gratuita e de qualidade. 
Dentre tantos mecanismos de luta merece destaque a IV Conferência Brasileira de Educação, (IV CBE), que teve curso em dezembro de 1986. Organizada por três das mais importantes entidades do campo no período: Associação Nacional de Educação (Ande), Associação Nacional de Pesquisa e Pós-Graduação em Educação (ANPEd) e Centro de Estudos Educação e Sociedade (Cedes), como antes já vinha ocorrendo. $\mathrm{O}$ evento congregou cerca de cinco mil participantes, objetivando debater os problemas da educação brasileira e a construção de propostas para a nova Constituição. Os resultados foram apresentados na Carta de Goiânia, que, além de uma análise da situação do País e da educação, apresenta 21 princípios como proposta a ser incorporada no texto da nova Carta. Entre eles, dois trataram da gestão democrática da educação, tomando-a como elemento indispensável à educação integral.

» O Estado deverá garantir à sociedade civil o controle da execução da política educacional em todos os níveis (federal, estadual e municipal), através de organismos colegiados, democraticamente constituídos.

» O Estado assegurará formas democráticas de participação e mecanismos que garantam o cumprimento e o controle social efetivo de suas obrigações referentes à educação pública, gratuita e de boa qualidade, em todos os níveis de ensino (IV CBE,1986: p. 9-10).

Ainda que a luta entre os projetos em disputa não tenha resultado na vitória do conjunto de proposições, sobretudo as relativas à democratização das estruturas do Estado e, portanto, da gestão da coisa pública, conseguimos registrar na Constituição a gestão democrática. Era um grande avanço para a época, na medida em que foi registrada como um dos princípios sobre os quais deve ser ministrado o ensino público (BRASIL, 1988).

Vale lembrar também que entre as reivindicações das forças progressistas esteve a descentralização das decisões e das políticas. O extremo centralismo que caracterizou os governos militares e mesmo a histórica tradição de decisões centralizadas, criou no imaginário nacional a identificação entre descentralização e democracia. Pode-se dizer que houve ganhos para grupos com distintos interesses, ao se considerar que os municípios se tornaram entes autônomos no novo pacto federativo firmado pela Constituição. Abriam-se possibilidades das políticas de educação serem construídas em face das especificidades locais e suas potencialidades, bem como a chance da população poder atuar no controle social dos governos locais.

Como ente federativo, o município ganhou a atribuição de "manter, com a cooperação técnica e financeira da União e do Estado, programas de educação pré-escolar e de ensino fundamental", recebendo o encargo da educação obrigatória. Os recursos foram constitucionalmente vinculados. A Constituição também prescreveu que a União, estados, 
o Distrito Federal e municípios organizariam em regime de colaboração seus sistemas de ensino (BRASIL, 1988).

Desde a promulgação da Constituição, é importante frisar que o debate sobre a gestão democrática não mais saiu de cena nesses 30 anos, o que se tornou um importante legado, mesmo que tenha estado mais presente na batalha das ideias e na legislação do que como método ou meio de atuação.

\section{As conquistas em risco}

O regime político democrático, nessas três décadas, favoreceu a organização de espaços de lutas, de debates e de proposições, que permitiram, em alguns momentos, o protagonismo das classes populares (e/ou de mediadores) em defesa dos seus interesses, a partir do alargamento de canais de participação nos espaços públicos e decisórios.

Graças às salvaguardas constitucionais, a organização do campo educacional fortaleceu-se, havendo o alargamento de muitos espaços de práticas democráticas na luta pelo usufruto do direito à educação por todos e todas, o que também se expressou no ambiente escolar. Isto, apesar de não termos de fato logrado a conquista desse direito; mas obtivemos avanços importantes em relação de onde partimos nos anos1980, como expressam pontos de inflexão que marcaram esses 30 anos.

Tal como previsto na Constituição, a gestão democrática foi reafirmada na Lei de Diretrizes e Bases da Educação Nacional (LDBEN), cujo processo de elaboração, tramitação e aprovação, além de bastante retardado, sofreu grandes turbulências. Mais uma vez esse processo trouxe para o centro da cena a não consideração, por parte de setores majoritários do poder legislativo e do poder executivo, das proposições que emanaram da sociedade civil organizada em torno dos interesses educacionais da maioria. O conservadorismo, novamente, impediu a aprovação de propostas que configurariam à educação um caráter republicano. Contudo, também obtivemos ganhos. Dentre os quais a própria lei reguladora e organizadora da educação em todo o território nacional e a reafirmação da gestão democrática (SAVIANI, 2011).

Vale lembrar que a gestão democrática na LDBEN ficou regulamentada por meio da participação dos atores escolares nas decisões e na articulação entre a escola e a comunidade. Estabeleceu-se, igualmente, a competência dos sistemas públicos de ensino na definição das normas da gestão democrática segundo suas especificidades, garantindo, para tanto, a participação dos profissionais da educação na elaboração do projeto pedagógico da escola, bem como a participação das comunidades escolar e local em conselhos escolares ou equivalentes. Os sistemas de ensino também passaram a ter como atribuição garantir que suas unidades escolares públicas de educação básica progressivamente alcançassem graus de 
autonomia pedagógica e administrativa e de gestão financeira, observadas as normas gerais de direito financeiro público (BRASIL, 1996).

Ainda em relação à legislação, e em obediência ao que prescreveu a Constituição e a LDBEN, após muitas tensões, em 2001 foi promulgado o primeiro Plano Nacional de Educação depois do regime autoritário (I PNE), com a vigência de dez anos. Novamente, o princípio da gestão democrática foi reafirmado, dentre outras formas, pelo estabelecimento de diretrizes que previram a criação de conselhos municipais de educação em nível de cada sistema de ensino e a formação de conselhos escolares nas escolas públicas, considerados mecanismos viabilizadores da gestão democrática. Entre os objetivos e metas do I PNE, registrou-se também o aperfeiçoamento do regime de colaboração entre os sistemas de ensino, de modo que se estabelecessem ações coordenadas entre os entes federativos a partir do compartilhamento de responsabilidades, tal como prescrito na Constituição e na LDBEN (BRASIL, 2001).

Lembramos que a promulgação da LDBEN e do I PNE se deu no período dos governos de Fernando Henrique Cardoso que se caracterizaram pelo aguçamento da difusão das terapias neoliberais entre nós, introduzidas durante o governo Collor de Mello. Preconiza-se, então, a premente necessidade de adequação das políticas de ajuste fiscal e das reformas, tal como defendidas pelo Consenso de Washington, como o único meio possível de o País voltar ao crescimento econômico e ao desenvolvimento, à semelhança do que assistimos agora. Desde aquele momento, os defensores de tal projeto se colocavam em posição contrária ao capítulo da Constituição que trata da Ordem Social (FAGNANI,2017). Portanto, contrários também a uma concepção e práticas educativas que tivessem por orientação a formação humana integral, explicitando nesse campo a constante tensão entre os que se colocam em defesa da solidariedade, dos direitos humanos e da democracia e os que se alinham aos interesses dos mercados financeiros globalizados em detrimento dos mercados internos, com consequências profundamente nefastas para as práticas solidárias, para o mundo do trabalho e para a educação como um direito universal.

Os marcos legais, ainda que indicassem a presença de consensos sobre a gestão democrática e, portanto, tratassem do alargamento da participação no espaço da formulação e das decisões sobre as questões da educação no âmbito dos sistemas de ensino e da própria escola, tinham subjacente concepções de gestão democrática, de descentralização e de participação que estavam orientando as práticas de política educacional dos governos de FHC segundo as diretrizes neoliberais. De acordo com essas diretrizes, a descentralização e a participação constituem instrumentos de modernização gerencial da escola pública, como de resto de outras instituições do Estado.

Começaram a ser introduzidas nas escolas práticas de quase mercado justificadas como meio de promover a eficácia e a eficiência na prestação dos serviços educacionais, seguindo receitas das agências internacionais. Essas receitas influenciaram reformas educacionais em escala planetária, buscando aproximar os processos educativos das necessidades dos 
mercados globalizados. Dentre as influências se situou um tipo de compreensão do fracasso escolar como decorrentes da precariedade da administração de recursos e da gestão.

O não privilegiamento da oferta da educação básica e sim do ensino fundamental para crianças e jovens na idade certa, a descentralização via municipalização e a adoção de práticas gerencialistas próprias das empresas e do mercado nas escolas, grosso modo, caracterizaram a gestão de FHC para o nível obrigatório da educação. Nesta direção houve a tentativa de se privilegiar a administração por projetos, com objetivos traçados previamente e com o envolvimento dos que fazem a escola e da comunidade, ressignificando-se a função do conselho gestor.

À introdução das práticas gerencialistas nas escolas e ao processo de descentralização, somou-se a ampliação de mecanismos de participação e de controle social da população na gestão. Além dos previstos na legislação, surgem no período uma multiplicidade de conselhos como os do Programa Nacional da Merenda Escolar, (PNME) do Livro Didático (PNLD), do Programa Dinheiro Direto na Escola (PDDE) do Fundo de Manutenção e Desenvolvimento do Ensino Fundamental e de Valorização do Magistério (Fundef) em todos os níveis da Federação.

Os conselhos trazem a população para a escola. Entretanto, o exercício da gestão democrática, na perspectiva do projeto de vida e de filosofia de ação, como defende Burdeau (1956), não se concretiza. A participação não se dá de modo espontâneo e não se encontra enraizada nas práticas cotidianas da população, sendo, em algumas situações, imposta. Impede, assim, de uma forma generalizada, o exercício da liberdade de expressão e de criação, caros para a gestão democrática.

Todavia, num movimento contraditório, a existência dos mecanismos de participação adquire importância, em virtude de sua ampla disseminação pelas unidades federativas e escolas (a depender de sua natureza), vindo a se constituir em espaços de resistência e de luta de acordo com as especificidades dos contextos. Em algumas situações permitiu a participação qualificada de pessoas de segmentos diversificados que trouxeram para a escola suas experiências de maior grau de politização, contribuindo para o alargamento de espaços de organização, elaboração e decisão.

Graças as salvaguardas constitucionais, também se tornou possível a ampla organização dos educadores em sindicados e associações de classe, e dos estudantes em suas entidades representativas, desde os grêmios escolares até agremiações de caráter nacional, permitindo-lhes atuação coletiva em defesa dos seus interesses e da educação no seu conjunto.

Esse legado, vindo dos governos de FHC, são incorporados pela nova coalizão que assume o poder de 2003 até 2016, capitaneada pelo Partido dos Trabalhadores, inicialmente tendo à frente o presidente Luiz Ignacio Lula da Silva (por dois mandatos 2003-2010), seguido pelos governos de Dilma Rousseff (2011-2016 dois mandatos com o segundo incompleto).

Esses governos prosseguiram com orientações neoliberais. Entretanto, num movimento ambíguo, que tendeu também para o atendimento dos interesses das classes populares, 
respeitando as regras do jogo democrático. Neste sentido, priorizaram a ampliação das arenas decisórias, estabelecendo gestões colegiadas como meio de democratização da gestão e prática das políticas sociais. É visível que as prioridades estabelecidas para as políticas sociais incidiam sobre as classes menos favorecidas, inclusive com o efetivo combate à pobreza.

Em relação a política educacional, vale ressaltar a prioridade em ampliar a educação obrigatória que passou a abranger a faixa etária de 4 a 17 anos de idade (incluindo a educação infantil e o ensino médio, além do ensino fundamental). O financiamento para tanto se materializou mediante a criação do Fundo de Manutenção e Desenvolvimento da Educação Básica e de Valorização dos Profissionais da Educação (Fundeb). Outro marco diferenciador desses governos foi a instituição do Piso Salarial Profissional do Magistério. Objetivando a formação inicial e continuada em nível técnico, o governo da presidenta Dilma privilegiou o Programa Nacional de Acesso ao Ensino Técnico e Emprego para os Jovens e o Programa Nacional de Educação Infantil, ações que pouco puderam se concretizar em função da crise, da paralisia e do golpe que acabaram por impedir a continuidade do seu segundo mandato.

No que se refere à gestão da educação, nesses governos houve a orientação para o fortalecimento da gestão democrática em todos os níveis e modalidades, articulando-a à melhoria da qualidade do ensino. Mesmo que não se tenha generalizado, e que as práticas gestionárias tenham se desenvolvido praticamente na mesma forma usado por FHC (por meio de programas e projetos), os conteúdos foram radicalmente distintos. Procurou-se reforçar valores efetivamente democráticos, buscando-se exercitá-los como prática de política, a partir do alargamento dos canais de participação que vinham sendo desenvolvidos.

Marcos essenciais da busca de abertura do processo decisório constituíram os processos pelos quais se desenvolveram as conferências de educação, mecanismos inovadores de participação da sociedade civil organizada na formulação do planejamento educacional de longo prazo. Em arenas conflituosas, mas onde forças contraditórias puderam se manifestar, tiveram curso as proposições, discussões e elaboração do II Plano Nacional de Educação, no transcurso de duas conferências nacionais como culminância de eventos semelhantes que aconteceram nas instâncias estaduais e municipais (DOURADO, 2011).

\section{O cômputo final}

Todas as lutas e conquistas, repetimos, são fruto de uma construção humana social e histórica. Desde então, podemos afirmar que as lutas, em maior ou menor grau, nunca mais se arrefeceram, sendo esta capacidade de luta um precioso legado que o campo educacional conseguiu preservar ao longo desses trinta anos de vigência da Constituição e, portanto, da ordem democrática ora ameaçada. É desta capacidade de luta, pois, que ora emerge a resistência contra as arbitrárias medidas de política que vemos se espraiar pelo País desde o golpe de 2016, bem como ao recrudescimento que 
se avizinha no anunciado projeto neoliberal e ultraconservador do governo eleito, e que será empossado em janeiro de 2019. A realidade, agora, como diz Ítalo Calvino, "é como um poço sem fundo. Voltamos a sentir o apelo do nada, a tentação de cair, de nos rejuntarmos a uma obscuridade que nos convoca". No entanto, há terapia: a nossa resistência.

Recebido em: 06/12/2018 e Aprovado em: 17/12/2018

\section{Notas}

1 Esta pesquisa contou com o apoio do Conselho Nacional de Desenvolvimento Científico e Tecnológico (CNPq).

2 Conforme estudo desenvolvido por Cardoso Junior (2018), de 1988 ao mês de levantamento em agosto de 2018, tinham sido aprovadas 105 emendas à Constituição.

3 Não há como não deixar de se associar certas medidas daquele momento com as propostas que hoje circulam na nossa sociedade consubstanciadas, dentre outras formas, no Movimento da Escola sem Partido e nos projetos de lei concernentes (Cf FRIGOTTO,2017, entre outros).

\section{Referências}

AZEVEDO, Janete Maria Lins de. Rumos da educação democrática sob o signo do autoritarismo. Um estudo sobre a política educacional no Brasil. Tese de doutorado-UNICAMP/ IFCH, Campinas, 1994.

. Democracia, democratização e conselhos. In: Antônio Bosco de Lima. (Org.). CMEs no Brasil qualidade social e política da educação. 1ed.São Paulo: Alínea, 2017, v. 1, p. 35-45.

.O Estado, a política educacional e a regulação do setor educação no Brasil: uma abordagem histórica. In: FERREIRA, Naura Syria Carapeto; AGUIAR, Márcia Angela da Silva. (Org.). Gestão da educação: impasses, perspectivas e compromissos. São Paulo: Cortez Editora, 2011.

. Implicações da nova lógica da ação do Estado para a educação municipal. Educação \& sociedade (impresso), campinas, v. 80, 2004.

BENEVIDES, Maria .Vitória. Cidadania e democracia. Lua Nova, n.33, 1996.

BURDEAU, Georges. La démocratie. Paris: Seuil, 1956

BRASIL. Lei № 9394/96, de 20 de dezembro de 1996. Estabelece as Diretrizes e Bases da Educação Nacional. Brasília. 1996.

Constituição da República Federativa do Brasil, 1988. 
CARDOSO JR., José Celso. CF 30 anos: da constituição cidadã à cidadania restrita. In: Frente ampla de trabalhadoras e trabalhadores do serviço público pela democracia. 30 anos da Constituição Federal Brasileira - Notas para um obituário precoce (1988/2018). Campinas: ARCA, 2018. p. 11-40.

COUTINHO, Carlos Nelson. Notas sobre a modernidade. In: Coutinho, Carlos N. Ensaios sobre a democracia e socialismo. Cortez, São Paulo: 2000.

CURY, Carlos Roberto Jamyl. Os Conselhos de Educação e a gestão dos sistemas. In: FERREIRA, Naura Syria Carapeto; AGUIAR, Márcia Ângela da Silva. (Org.). Gestão da educação: impasses, perspectivas e compromissos. São Paulo: Cortez Editora, 2011.

DARDOT, Pierre; LAVAL, Christian. A nova razão do mundo: ensaio sobre a sociedade neoliberal. São Paulo: Boitempo, 2016.

DEWEY, Jonh. Democracia e educação. São Paulo: Companhia Editora Nacional, 1959.

DOURADO, Luiz Fernandes (Org.). Plano Nacional de Educação 2011-2020: avaliação e perspectivas. 2. ed. Goiânia/Belo Horizonte: UFG/Autêntica, 2011. 344p.

FAGNANI, Eduardo. O fim do breve ciclo da cidadania social no Brasil (1988-2015), Texto para Discussão n. 380. Campinas: Instituto de Economia da Unicamp, Junho, 2017.

FRIGOTTO, Gaudêncio.(org.) Escola "sem" partido: esfinge que ameaça a educação e a sociedade brasileira. Rio de Janeiro: UERJ, LPP, 2017.

A produtividade da escola improdutiva. São Paulo: Cortez, 1984.

FREIRE, Paulo. Educação como prática da liberdade. Rio de Janeiro: Paz e Terra, 1974.

GUIMARÃES, Ulisses. Discurso do Presidente da Assembléia Nacional Constituinte em 5 de outubro de 1988, Carta social e do trabalho, n. 37, Campinas: IE /UNICAMP, Jan.- Jul, 2018.

GERMANO, José Willington. Estado Militar e Educação no Brasil (1964-1985). 5. ed. São Paulo: Cortez, 2011.

IV CBE. Carta de Goiânia. Revista Educação \& Sociedade, Campinas, Cedes, n. 25. São Paulo: Cortez Editora, 1986.

MANNHEIM, Karl. Libertad, poder y planificacion democrática. México: Fondo de Cultura, 1960.

MULLER, P. Les politiques publiques. Paris: PUF, 1990.

NERY JUNIOR, Nelson; NERY, Rosa Maria Barreto Borriello de Andrade. Constituição federal comentada e legislação constitucional. 4. ed. São Paulo: Revista dos Tribunais, 2013.

PRZEWORSKI, Adam; WALLERSTEIN, Michael. O capitalismo democrático na encruzilhada. Novos Estudos CEBRAP, São Paulo, CEBRAP, n. 22, outubro de 1988.

SAVIANI, Dermeval. A nova lei da educação: trajetória, limites e perspectivas. 12. ed. Campinas: Autores Associados, 2011. 